\title{
A Prototype of Web-based Picture Cards Matching Video Game for Memory Improvement Training
}

\author{
Harya Bima Dirgantara ${ }^{1}$, Henri Septanto ${ }^{2}$ \\ ${ }^{1,2}$ Informatics, Kalbis Institute, Jakarta, Indonesia \\ ${ }^{1}$ harya.dirgantara@kalbis.ac.id
}

Accepted on August 03, 2020

Approved on October 09, 2020

\begin{abstract}
This study aims to design an action-arcade web-based picture card matching video game for memory improvement. Picture cards to be matched are animals that usually exist in zoos and farms, like monkey, cow, dog, pig, chicken, zebra, elephant, owl, and mouse. This research uses the prototyping process model with the communication stage, quick planning, modeling, construction, and launching. The results of this study are web-based video games for memory improvement training. From the results of the user experience testing, $68 \%$ of respondents informed that they felt it was easier to remember.
\end{abstract}

Index Terms - action-arcade; memory improvement training; picture cards matching; prototyping; video game

\section{INTRODUCTION}

Video games are proven to increase social development and cognitive abilities. However, too much video game playing can cause some negative aspects, such as negative social traits, addictions, and health problems [1]. Research in [2], state that video games also give motivational benefits to the players. The action-arcade game could stimulate cognitive abilities. Action-arcade games are a type of game that is played without the need to think hard, but fast, so it requires specific techniques to solve problems. Arcade games can take place on one screen or several [3]. Research in [4] [5] [6], state that action-arcade games have the potential to train someone's cognitive abilities.

Arcade games have sub-genres including the maze, pong, shooter, puzzle, or platformers. Arcade games also allow players to unite visual vocabulary learning that can be used to train memory [7]. Arcade games are more interesting if they have a theme and adapted to the location of the players. This theme referred to as localization. Localization is a simple process, which translates text or terms into the local language where the game is released. Localization is also done to accommodate cultural differences in each place where the game is released [8].
Digital video games make learning more fun and exciting and help players to retain and recall information [9]. Video games could have a massive effect on living and learning [10]. Video games can trigger social development and cognitive abilities, Too much video game playing might resulting in negative social traits, addiction, even health problem [1] [11]. Web-based games are widely used to teach reading, mathematics, and science. Web-based games are games with a specific purpose [12]. The learners' motivation and confidence can be enhanced in the process of playing a game when they achieve learning goals in a relaxing environment [13], as cited in Temaja [14].

Cognitive abilities such as memory can be enhanced with video games, such as a memory matrix training game. In this game, players were shown a $3 \times 3$ matrix in which tiles lit up in a sequence [15] [16]. Players were then instructed to reproduce the series by touching the location of each tile sequentially in the matrix. There are four principles of memory improvement: process material actively, practice retrieval, use distributed practice and use metamemory [17]. Matching activities such as matching game improves language, concentration, and memory [18].

Based on this background, this research aims to build a web-based image matching video game for memory improvement. The game design in this research is based on the principles of memory improvement, especially practice retrieval and use distributed practice principles. The players must match the same image card to get a score. The position of the picture is initially closed, if the player chooses the card with the same picture, they will get a score, and the map will be opened. The image that will be used is the characteristic fauna in Indonesia. The game has four difficulty levels: easy, normal, hard, and extreme. This study uses prototyping model process because it requires suggestions from the users for further work and development. 


\section{LITERATURE REVIEW}

\section{A. Video Game}

According to Salen \& Zimmerman [19], the game is an activity with some rules engaged in for an outcome. The video game is the application of human and computer interaction [20]. Another definition of a video game is a game we play thanks to an audiovisual apparatus and which can be based on a story [21]. Every video game has "bricks" which are [22]): "game": if the rule is directly related to the goal of the game, mainly as feedback within the rule effects and "play": if the rule template is independent of the goal. The rule is then characterized by a trigger based on the video games input.

The video game has several goals: collect something, gain territory, get somewhere first, remove a series of obstacles, discovery, and eliminate other players [23]. A video game can be an integral of modern pedagogy [24]. There are three game elements in a working memory training: progress bar, level indicator, and thematic setting [25]. Video game training increases memory in different aspects, such as visuospatial, episodic memory short-term memory, and mnemonic discrimination [26].

\section{B. Action-arcade Video Game}

An action video game is a video game that offers the intensity of some action as the primary attraction and interaction [27]. Action game is a response-based video game [28] [29]. Action game involves lots of frantic button pushing [23]. An arcade game is a video game that are not focused on the game's storyline, but only for a moment of fun and chasing the highest score [30].

Action-arcade game is video games that require a fast reaction from the players and can be a useful exercise for cognitive improvement [31]. The focus of the action-arcade game is on the user's responses and reflexes. The game often features puzzle-solving, image matching, complex thinking, or strategy [32]. The action-arcade game has the potential to be an exciting learning tool by adding educational gameplay features. Playing an action-arcade game can improve cognitive abilities, improve visual-spatial resolution, and creativity [33].

\section{Memory}

Memory is the section of the brain by which data is encoded, stored, and retrieved when needed, then influencing future action [34]. Memory is defined as the application of learning over time [35]. There is four principles memory improvement defined broadly as follow [17]:

- Process material actively. It means to emphasize and elaborative processing, sometimes also known as a meaningful process [36].

- Practice retrieval. It means to learn by recalling information from memory. Retrieval practice can lead to more learning than restudying [37] [38].

- Use distributed practice. It means the learning process is spread out across relatively long periods. The distributed practice may be the most powerful method for people to improve their memory without changing the amount of time spent studying [39].

- Use metamemory. It refers to judgement and decisions about learning and memory [40] [41] [42].

\section{Matching Game}

A matching game, as cited in [43] is a game that the player turns over two cards at the same time to turn over a matching pair by using their memory [44].

\section{E. Prototyping Model Process}

Prototyping model process can be used to develop software or game. According to Pressman [45], the prototyping model process is consists of five stages:

- Communication. In this stage, we define the overall game objectives and identify the requirements.

- Quick plan. We are planning the game feature briefly and quickly.

- Modelling quick design. Performing game design using modelling tools such as flowchart and mockup interface design.

- Construction of prototype. Coding the game prototype and testing the game.

- Deployment delivery \& feedback. The game is launched to the user and asks for feedback.

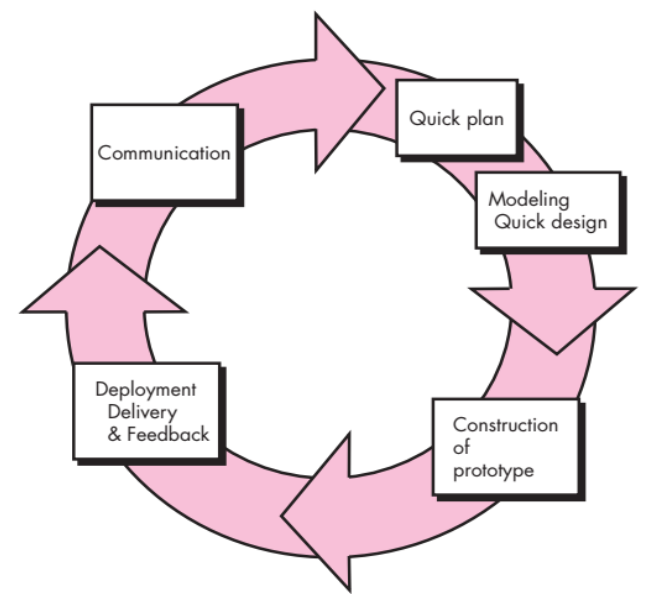

Fig. 1. Prototyping model process [45] 


\section{F. $\quad$ Related Works}

There are some similar works that form the foundation of this research. Research by Temaja [14], the result is an e-matching game can be used for creating fun and productive learning activity for young learners. The study by Dirgantara \& Marselino [46], the result is a web-based learning media that is accessible to the public. Based on this research, $97 \%$ of respondents stated the learning media is succeeding for study.

Research by Khenissi et al. [47], the result is a memory match game to render the learning experience with more fun, to engage learners and to keep them motivated. Research by Dirgantara et al. [11], the result is a quiz video game for learning mathematics with the theme of wizard battle. The theme makes a fun and pleasant learning environment. These research are the foundation of this research to develop a web-based game for learning media.

Research by Buschkuehl et al [48] and Loosli et al [49] as cited in Deveau et al [50], state that if animal pictures are presented sequentially and participants respond to the each of image would be a good training approach to promote learning. This research is the reason to using animal object as game assets.

Research by Hartshorne [51], state that the speed in processing information reaches its peak at the age of 18-19 years old, then gradually decreases thereafter. Short-term memory continues to develop and builds up until around age 25 , then starts to stagnate and eventually declines slowly starting at age 35 . This research is the reason why the respondents are 18 years old or older.

\section{RESEARCH METHODOLOGY}

\section{A. Communication Stage}

At this stage, it was carried out between the research team and prospective respondents. Communication is carried out to obtain input features or displays that are easy to use. From the communication results obtained by the user requirements as follows:

- The player who correctly matches the picture gets a score.

- The player who correctly matches images at least 2 times in a row will get an additional bonus score.

- The game consists of 4 difficulty levels.

- High score leaderboard menu.

- There are sound effects.

- Help menu.
- Cards are arranged randomly each time the game starts.

- The main target audiences for the game is the general public aged 18 years or older.

The gameplay derived from the user requirements is adapted to use distributed practice principle for memory improvement. The system requirements to be able to play this game prototype are as follows:

- The latest browser application, preferably Google Chrome or Mozilla Firefox.

- It is connected to the internet.

- Minimum of 2GB RAM

\section{B. Quick Plan Stage}

At this stage, resource planning and features in the designed game are carried out. The flow of this game is displayed in Fig. 2. The game starts with the player choosing the difficulty level of the game: easy, normal, hard, or extreme. At the easy difficulty level, the number of picture cards is 16 with 4 rows and 4 columns. At the normal difficulty level, the number of picture cards is 24 with 4 rows and 6 columns. At the hard difficulty level, the number of picture cards is 32 with 4 rows and 8 columns. At the normal difficulty level, the number of picture cards is 40 with 4 rows and 10 columns.

If the cards are not all open, then the player can choose a card to be matched if the cards opened are matched, then the player gets ten scores. If the cards are not matched, the player does not get a score. If the player managed to match the picture cards, then the player will get a score by calculating the formula: (consecutive matches * 10). When all the cards have been opened then the game is finished and will be directed to the high score menu.

The resources used to design this game are Game Maker Studio 1.4 and various open-source assets that are used as game objects. The list of assets is shown in Table I. The assets used are pictures and sound. 


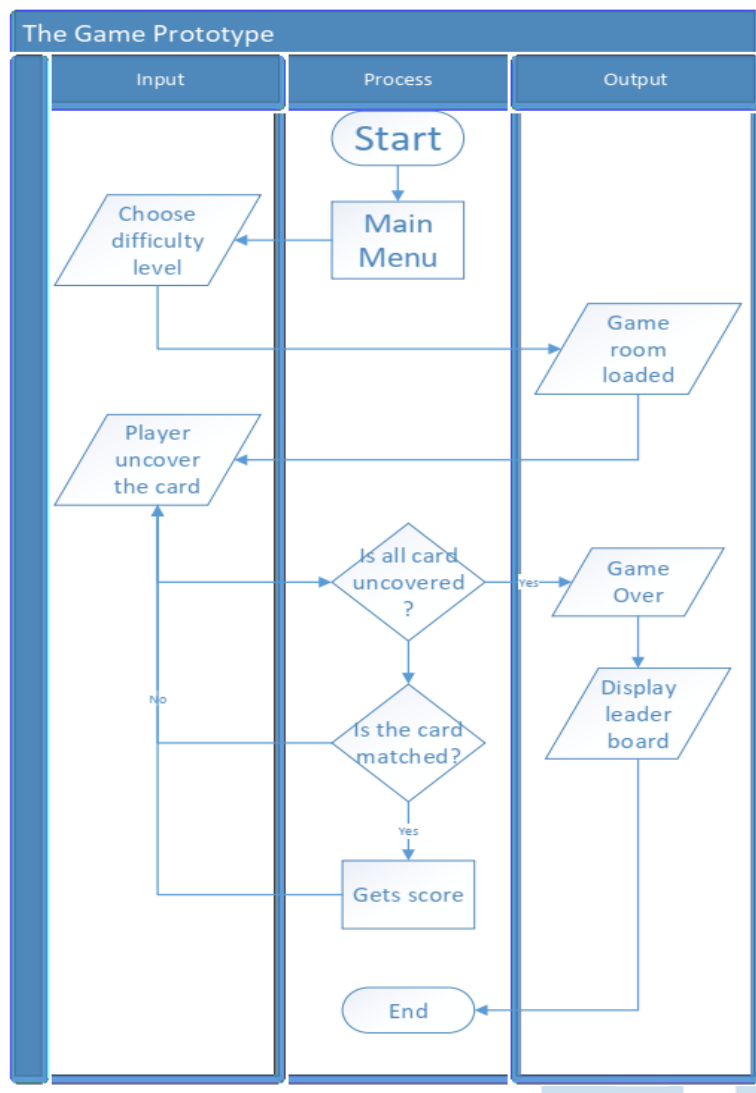

Fig. 2. The game prototype flowchart

TABLE I. THE GAME ASSETS

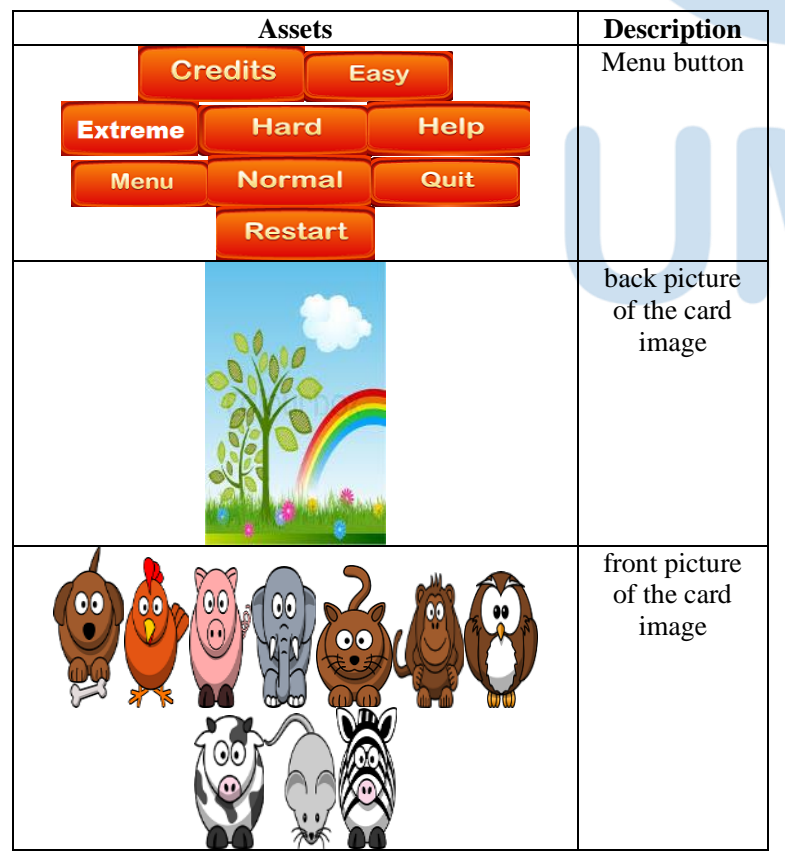

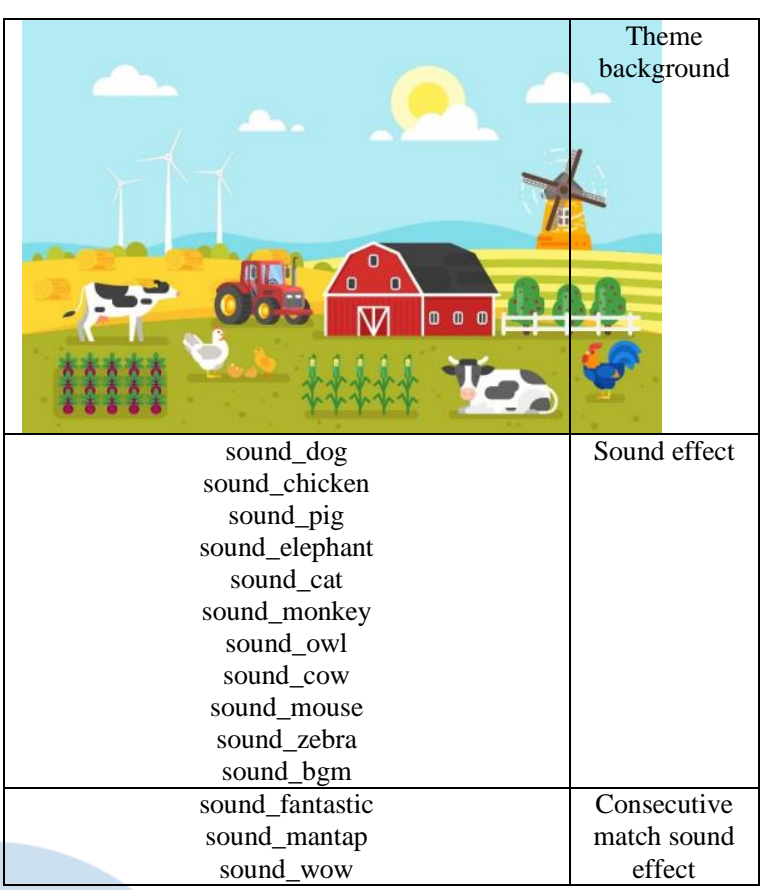

The game assets are consist of images and sounds. The images are divided into four categories: menu button image (credit, easy, normal, hard, extreme, help, menu, quit, and restart) credit to Poconk Game Artist [52], back picture of the card image credit to Get4art [53], front picture of the card image (dog, chicken, pig, elephant, cat, monkey, owl, cow, mouse, and zebra) credit to Dansie [54], and the game theme background image. The sounds are divided into two categories: the sound effect (dog, chicken, pig, elephant, cat, monkey, owl, cow, mouse, zebra, and background music) credit to Soundbible [55] and the consecutive match sound effect that will sound if the player manages to match the card in a row credit to amateur voice actress Benedikta Prava Krista Galuh Jiwantari.

\section{Modelling Quick Design Stage}

At this stage, the application modelling is carried out using Balsamic application to illustrate the application's display design. The interface designs of the game are shown in Fig. 3 to Fig. 5 . 


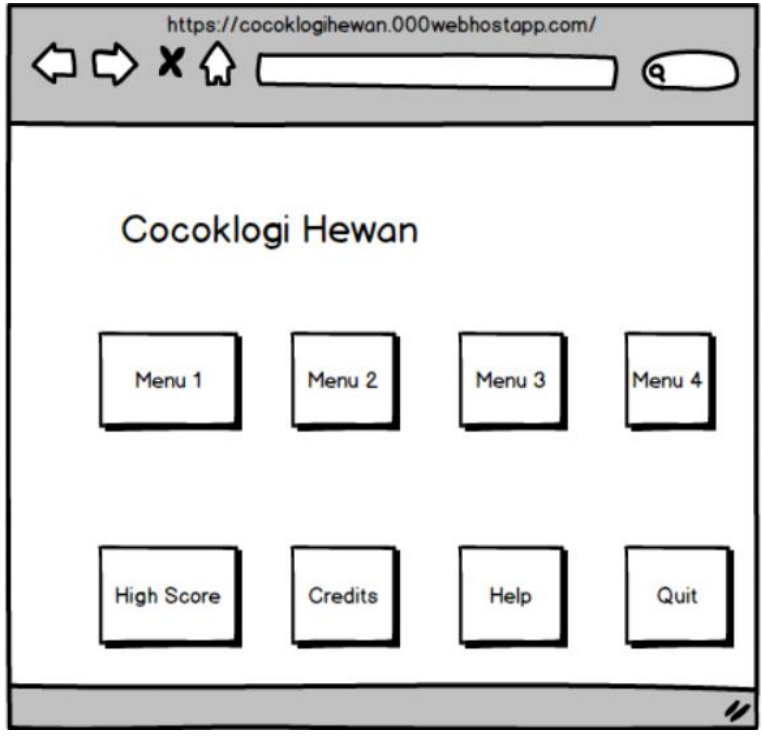

Fig. 3. The game main menu

Fig. 3 shows the initial game layout design contains menus that can be selected by the player. There is menu 1 - menu 4, which is the choice of difficulty level, high score menu, credits, help and quit. After the player chooses one of the difficulty level menus, it will be directed to the game screen.

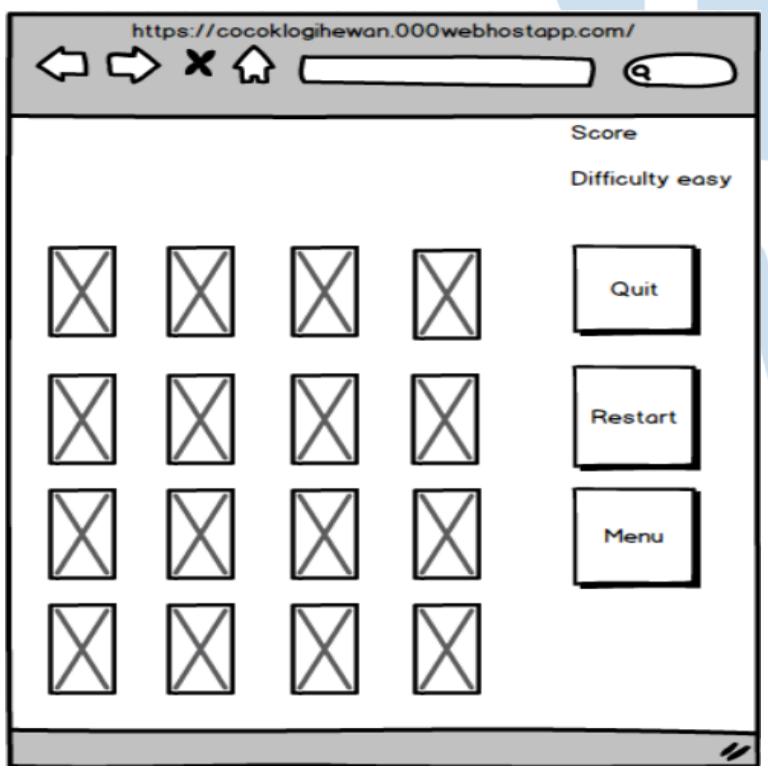

Fig. 4. The gameplay screen

Fig. 4 displays the appearance of the game page on the easy difficulty level. 16 cards are still closed, and players can start to open cards to be matched, if they are matched, they will get a score of 10. Fig. 5 displays a high score screen that contain the player's name and the score.

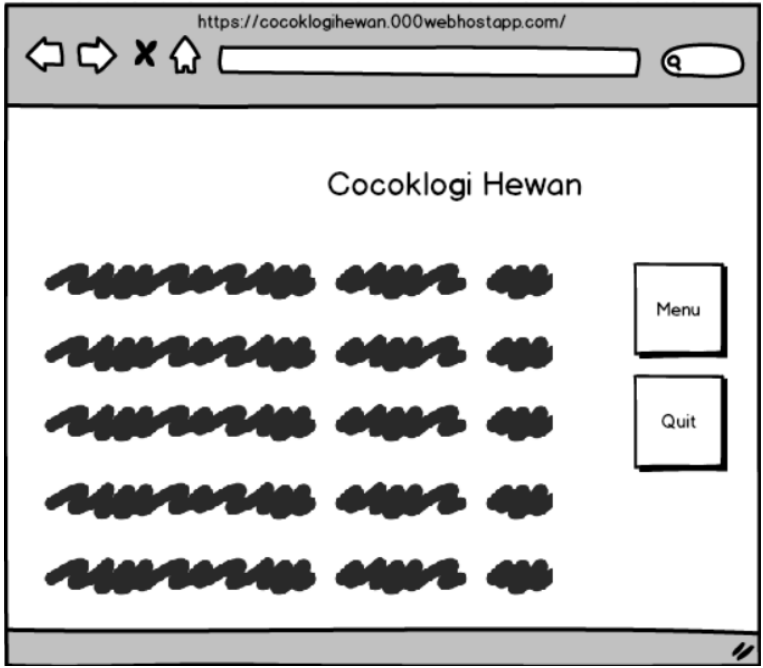

Fig. 5. The high score screen

\section{Construction Stage}

At this stage, the game development is carried out. Coding is done using Game Maker Studio 1.4. The game construction used the Drag $\mathrm{n}$ Drop (DnD) method and programming using the Game Maker Language (GML). This application development requires six rooms. These six rooms are used to execute the code that has been created. The rooms list is shown in Table II.

TABLE II. THE ROOM LIST

\begin{tabular}{|c|c|}
\hline Room name & Description \\
\hline Room_start & The game main menu \\
\hline Room_help & The game description \\
\hline Room_game_easy & The game room of easy difficulty level \\
\hline Room_game_normal & The game room of normal difficulty level \\
\hline Room_game_hard & The game room of hard difficulty level \\
\hline Room_game_extreme & The game room of extreme difficulty level \\
\hline
\end{tabular}

The game rooms are shown in Fig. 6 to Fig. 11 . Fig. 6 shows the game's main menu. It consists of six lists: Easy, Normal, Hard, Extreme, Help, and Quit. Fig. 7 shows the game description and how to play the game. 


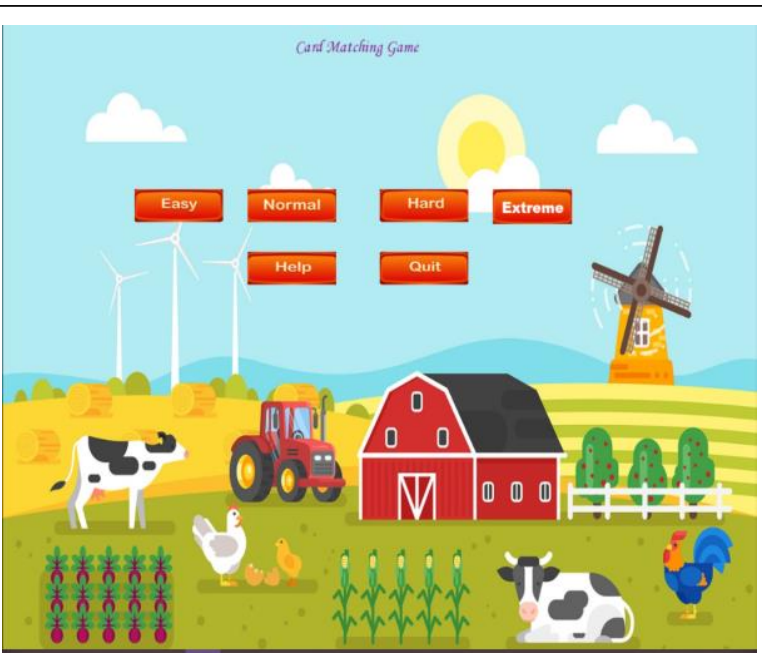

Fig. 6. Main menu

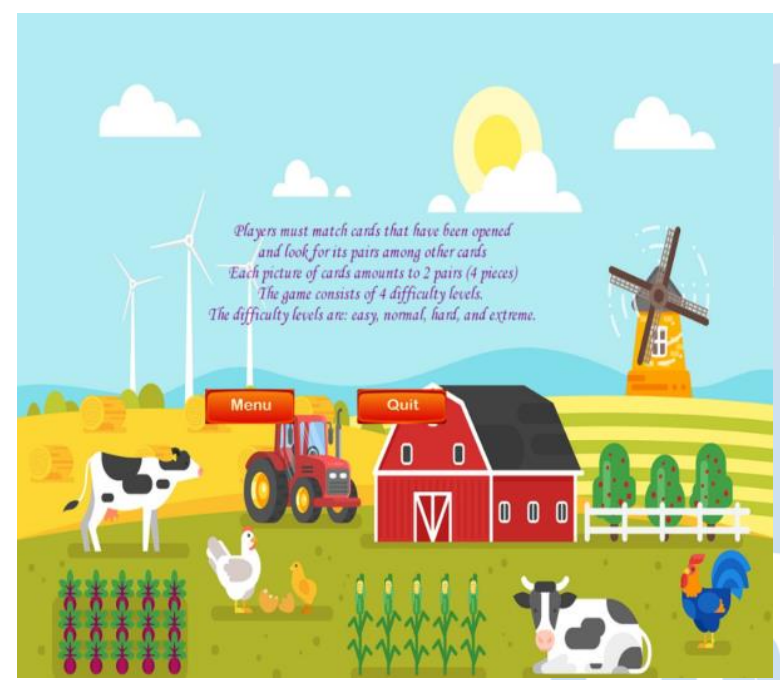

Fig. 7. The help menu

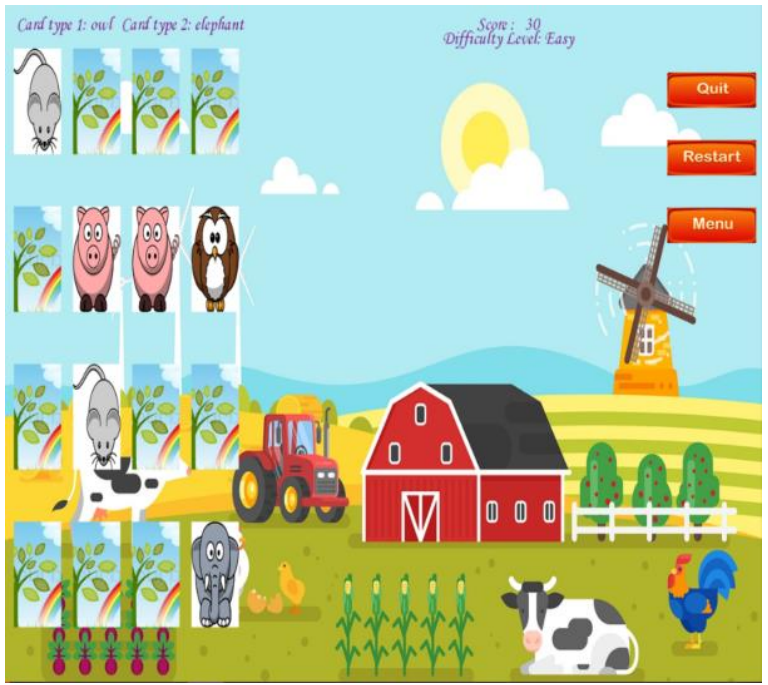

Fig. 8. The easy difficulty

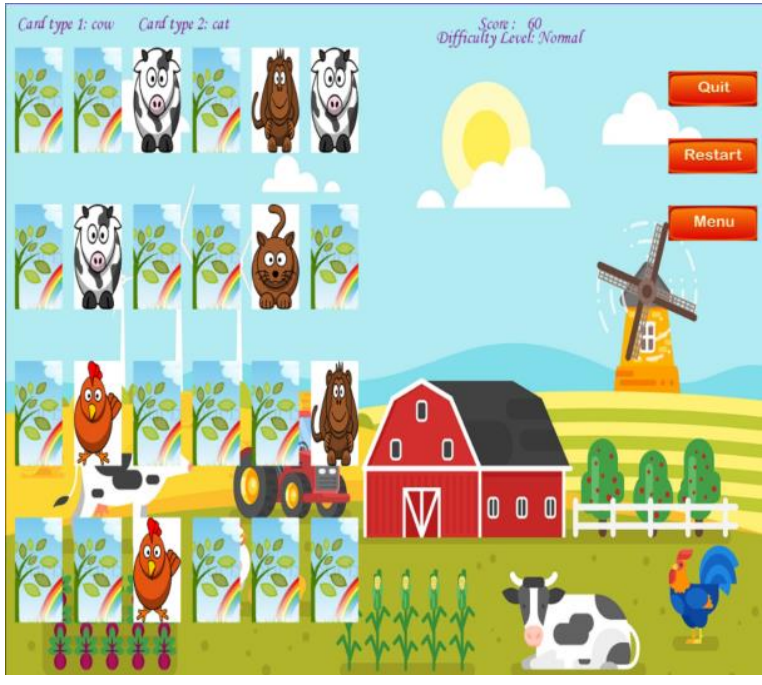

Fig. 9. The normal difficulty

Fig. 8 to Fig. 11 shows the playroom for each difficulty level. The easy difficulty level has 16 cards to match which arranged in 4 rows and 4 columns. The normal difficulty level has 24 cards to match which arranged in 4 rows and 6 columns. The hard difficulty level has 32 cards to match which arranged in 4 rows and 8 columns. The extreme difficulty level has 40 cards to match which arranged in 4 rows and 10 columns.
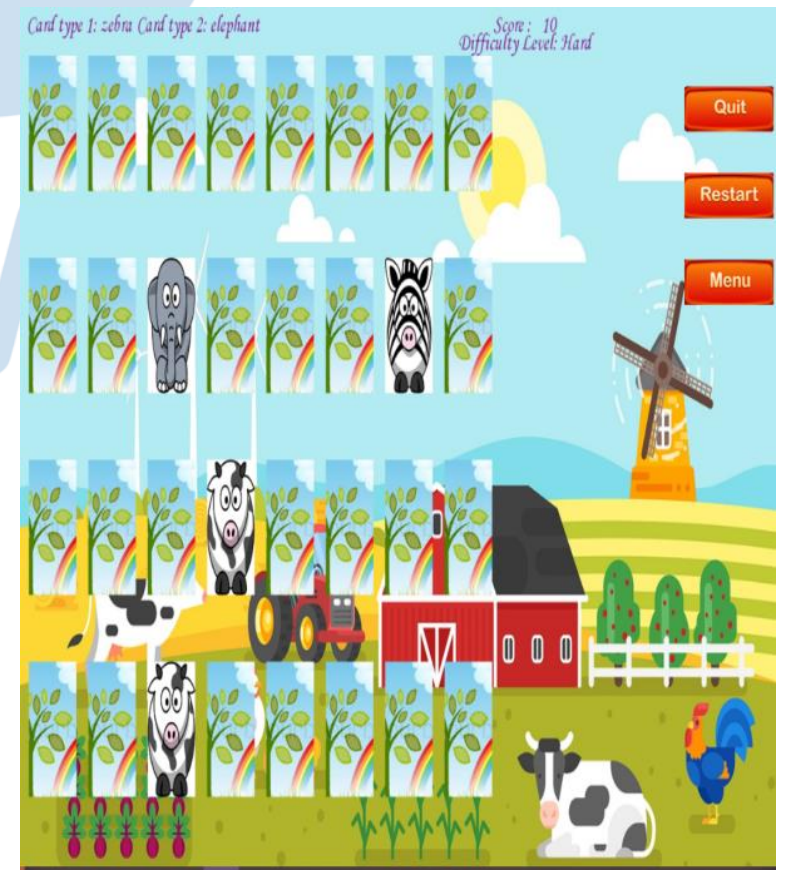

Fig. 10. The hard difficulty 


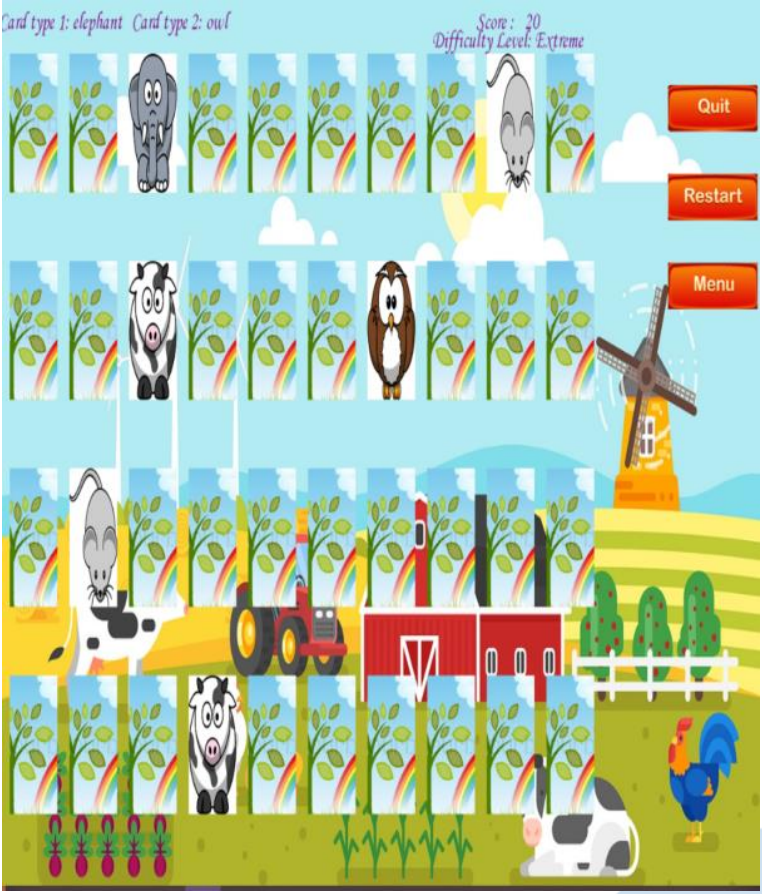

Fig. 11. The extreme difficulty

Fig. 12 shows the notification "You Win!" after all the cards opened.

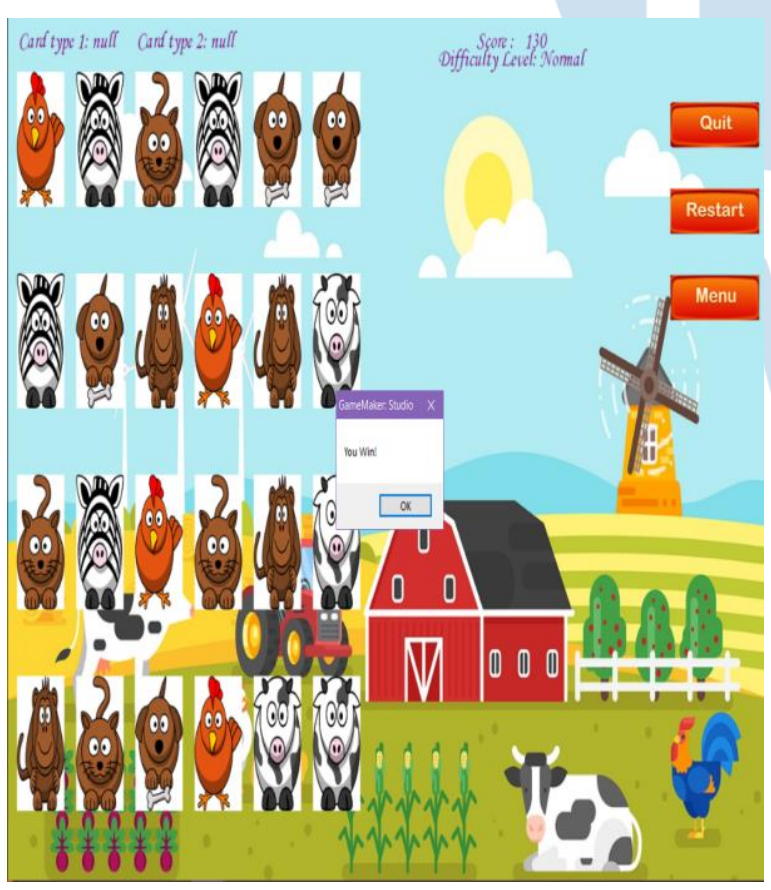

Fig. 12. Win notification

\section{E. Deployment Delivery and Feedback Stage}

At this stage, delivery and application execution is carried out to prospective computer game users. The specific testers are asked to provide feedback. The tester criteria is familiar with playing a game. The respondents are aged 18 to 20 years old. There are 31 respondents to test the game prototype. The list of user experience testing questions is shown in Table III.

TABLE III. USER EXPERIENCE TESTING QUESTION

\begin{tabular}{|l|l|}
\hline Number & \multicolumn{1}{|c|}{ Question } \\
\hline 1 & Is the game easy to understand? \\
\hline 2 & $\begin{array}{l}\text { Are the images in the game clear and easy to } \\
\text { distinguish from other cards? }\end{array}$ \\
\hline 3 & $\begin{array}{l}\text { After playing this game, do you find it easier to } \\
\text { remember? }\end{array}$ \\
\hline
\end{tabular}

The user experience participants were the first year Informatics students. The user experience testing results shown: all of the respondents stated that the game is easy to understand, easy to understand images, easy to distinguish from other cards, 21 respondents said that after they play the game, they felt it was easier to remember.

\section{CONCLUSION AND FUTURE WORKS}

This study can be concluded as follows:

- Based on the game prototype, 21 respondents (68\% from 31 respondents) stated that after they play the game, they felt it was easier to remember.

- If this game is accessed using Google Chrome, sometimes the sound effect doesn't work according to its function, whereas in Mozilla Firefox, the sound effects run according to its purpose.

- The matching game activities are aligned with the use distributed practice principles to enhance memory.

- There are four difficulty levels add challenges to the game.

The future works of this study are to add a timer in each difficulty level, combining the variation of the card, adding punishment system, release the game to the public and add public respondents to measure the memory enhancement.

\section{ACKNOWLEDGMENT}

The Authors thanks to Institut Teknologi dan Bisnis Kalbis for funding this research.

\section{REFERENCES}

[1] A. Mitchell dan C. Savill-Smith, The use of computer and video games for learning, Ultralab, 2004.

[2] D. Johnson dan J. Gardner, "Personality, Motivation and Video Games," in Conference: Proceedings of the 22nd Australasian Computer-Human Interaction Conference OZCHI 2010, Brisbane, 2010.

[3] A. Feldman, Designing Arcade Computer Game graphic, Texas: Wordware Publishing, 2001, pp. 10-13. 
[4] S. Chandra, G. Sharma, A. A. Salam, D. Jha dan A. P. Mittal, "Playing Action Video Games a Key to Cognitive Enhancement," in 7th International conference on Intelligent Human Computer Interaction, IHCI 2015, 2015.

[5] D. G. Gozli, D. Bavelier dan J. Pratt, "The Effect of Action Video Game Playing on Sensorimotor Learning: Evidence From a Movement Tracking Task," Human Movement Science, vol. 38, pp. 152-162, 2014.

[6] D. Eseryel, X. Ge, D. Ifenthaler dan V. Law, "Dynamic modeling as a cognitive regulation scaffold for developing complex problem-solving skills in an educational massively multiplayer online game environment," Journal of Educational Computing Research, vol. 45, no. 3, pp. 265-286, 2011.

[7] C. J. Cai, "Adapting Arcade Games for Learning," in Conference on Human Factors in Computing Systems, Paris, 2013.

[8] M. B. Merino, "On the Translation of Video Games," The Journal of Specialised Translation, no. 6, pp. 22-36, 2006.

[9] Y.-J. An dan L. Cao, "The Effects of Game Design Experience on Teachers' Attitudes and Perceptions regarding the Use of Digital Games in the Classroom," TechTrends, vol. 61, pp. 162-170, 2017.

[10] B. E. Shelton, "Is Educational Game Research Doomed to Fail?," TechTrends, vol. 52, no. 5, pp. 74-75, 2008.

[11] H. B. Dirgantara, Y. D. Prabowo dan M. M. Jermia, "Development of Android-based Quiz Video Game: Mathventure," in 2019 International Joint Conference on Information, Media and Engineering (IJCIME), Osaka, 2019.

[12] R. Hamm, L. Pinkus, A. Wilkins dan M. Town, "The Impact of Web-Based Game Play on Soft Skills Education," 2015. [Online].

Available: https://www.semanticscholar.org/paper/The-Impact-of-WebBased-Game-Play-on-Soft-Skills-Hamm-

Pinkus/b5440a8b03f6f9403849c722da6183cd2563f86b.

[13] Y. C. Chan dan L. C. Lin, "Competitive and Cooperative Games in EFL Elementary School Classroom," in Proceedings of ROCMELLA 2000, Taipei, 2000.

[14] I. G. B. W. B. Temaja, "E-Mathing Game in Teaching English for Young Learners," PEOPLE: International Journal of Social Sciences, pp. 67-79, 2017

[15] A. C. Oei dan M. D. Patterson, "Enhancing Cognition with Video Games: A Multiple Game Training Study," Plos One, vol. 8, no. 3, 2013

[16] P. L. Baniqued, M. B. Kranz, M. W. Voss, H. Lee, J. D. Cosman, J. Severson dan A. F. Kramer, "Cognitive training with casual video games: Points to consider," Frontiers in Psychology, vol. 4, no. 1010, pp. 1-19, 2014.

[17] B. L. Schwartz dan L. K. Son, "Four Principles of Memory Improvement: A Guide to Improving Learning Efficiency," The International Journal of Creativity \& Problem Solving, vol. 21, no. 1, pp. 7-15, 2011.

[18] Surrey Early Years and Childcare Service, "Surrey County Council," 2017. [Online]. Available: surreycc.gov.uk/_data/assets/pdf_file/0006/88134/Matchingactivities.pdf.

[19] K. Salen dan E. Zimmerman, Rules of Play: Game Design Fundamentals, New York City: MIT Press, 2003.

[20] J. A. Newman, Videogames, 2nd edition., London and New York: Routledge, 2004.

[21] N. Esposito, "A Short and Simple Definition of What a Videogame Is," in Proceedings of DiGRA 2005 Conference: Changing Views - Worlds in Play, Vancouver, 2005.

[22] D. Djaouti, J. Alvarez, J.-P. Jessel, G. Methel dan P. Molinier,
"A Gameplay Definition through Videogame Classification," International Journal of Computer Games Technology, 2008.

[23] A. Rollings dan D. Morris, Game Architecture and Design: A New Edition, Indianapolis: New Riders, 2004, pp. 121-132.

[24] N. DeKanter, "Gaming Redefines Interactivity for Learning," TechTrends, vol. 49, no. 3, pp. 26-31, 2005

[25] M. Ninaus, G. Pereira, R. Stefitz, R. Prada, A. Paiva, C. Neuper dan G. Wood, "Game elements improve performance in a working memory training task," International Journal of Serious Game, vol. 2, no. 1, pp. 1-16, 2015.

[26] Y. Cao, "The Influence of Video Game Intervention on the Memory of the Elderly," in 2018 International Workshop on Education Reform and Social Sciences (ERSS 2018), 2018.

[27] L. Grace, "Game Type and Game Genre,” 2005.

[28] B. Gros, "Digital games in education: The Design of Games Based Learning Environments," Journal of Research on, vol. 40, no. 1, pp. 23-39, 2007.

[29] D. Vlachopoulos dan A. Makri, "The effect of games and simulations on higher education: a systematic literature review," International Journal of Educational Technology in Higher Education, vol. 14, no. 22, 2017.

[30] T. Donovan dan R. Garriott, Replay: The history of video games, Lewes: Yellow Ant, 2010, pp. 20-34.

[31] S. R. Siegel, B. L. Haddock, A. M. Dubois dan L. D. Wilkin, "Active Video/Arcade Games (Exergaming) and Energy Expenditure in College Students," International Journal of Exercise Science, vol. 2, no. 3, pp. 165-174, 2009.

[32] Moby Games, "Moby Games Genre Definition," 2014. [Online]. Available: https://www.mobygames.com/glossary/genres.

[33] I. Granic, A. Lobel dan R. C. M. E. Engels, "The Benefits of Playing Video Games," American Psychologist, vol. 69, no. 1, pp. 66-78, 2013.

[34] L. Sherwood, Human Physiology: From Cells to Systems, Cengage Learning, 2015.

[35] C. P. May dan G. O. Einstein, "Memory," American Psychological Association, 2013.

[36] F. I. M. Craik dan R. S. Lockhart, "Levels of processing: A framework for memory research," Journal of Verbal Learning and Verbal Behavior, vol. 12, pp. 671-684, 1972.

[37] H. L. Roediger dan J. D. Karpicke, "The power of testing memory: Basic research and implications for educational practice," Perspectives on Psychological Science, pp. 181-210, 2006.

[38] H. L. I. Roediger, "The Critical Role of Retrieval in Enhancing Long-Term Memory: From the Laboratory to the Classroom," Keynote address at the 50th annual Psychonomics meeting, Boston, 2009.

[39] N. Kornell, "Optimising learning using flashcards: Spacing is more effective than cramming," Applied Cognitive Psychology, pp. 1297-1317, 2009.

[40] J. D. Karpicke, "Metacognitive control and strategy retrieval: Deciding to practice retrieval during learning," Journal of Experimental Psychology: General, vol. 138, pp. 469-486, 2009.

[41] J. Metcalfe, "Metacognitive judgments and control of study," Current Directions in Psychological Science, vol. 18, pp. 159$163,2009$.

[42] L. K. Son, "Metacognitive control and the spacing effect," Journal of Experimental Psychology: Learning, Memory, and Cognition, vol. 36, pp. 255-262, 2010. 
[43] B. F. Klimova, "Games in the Teaching of English," Procedia - Social and Behavioral Sciences, vol. 191, pp. 1157-1160, 2015.

[44] J. Hadfield, Elementary vocabulary games, Harlow: Pearson Education Limited, 1998.

[45] R. S. Pressman, Software Engineering: A Practitioner's Approach, 7th edition., New York: McGraw-Hill, 2010, pp. 52-56.

[46] H. B. Dirgantara dan T. L. Marselino, "Development of Webbased Matrix Operations Calculation as a Learning Media," International Journal of New Media Technology, vol. 4, no. 2, pp. 105-111, 2017.

[47] M. A. Khenissi, F. Essalmi, M. Jemni dan D. Kinshuk, "A Learning Version of Memory Match Game," in Conference: 2014 IEEE 14th International Conference on Advanced Learning Technologies (ICALT), Athens, 2014.

[48] M. Buschkuehl, S. M. Jaeggi, S. Hutchison, P. Perrig-Chiello, C. Däpp dan M. Müller, "Impact of Working Memory Training on Memory Performance in Old-old Adults," Psychol. Aging, vol. 23, pp. 743 -753, 2008.

[49] S. V. Loosli, M. Buschkuehl, W. J. Perrig dan S. M. Jaeggi, "Working Memory Training Improves Reading Processes in Typically Developing Children," Child Neuropsychology, vol. 18, pp. $62-78,2011$.

[50] J. Deveau, S. . M. Jaeggi, V. Zordan, C. Phung dan A. R. Seitz, "How to Build Better Memory Training Games," Frontiers in System Neuroscience, vol. 8, no. 243, pp. 1 - 7, 2015.

[51] J. . K. Hartshorne dan L. T. Germine, "When Does Cognitive Functioning Peak? The Asynchronous Rise and Fall of Different Cognitive Abilities Across the Life Span," Psychological Science, vol. 26, no. 4, pp. 433 - 443, 2015.

[52] Poconk, "Game Dev Market," 28 Januari 2015. [Online]. Available: https://www.gamedevmarket.net/asset/free-gamebutton-pack-1906/. [Accessed Oktober 2018].

[53] get4art, "Feature Pics," 2018. [Online]. Available: https://www.featurepics.com/online/Nature-Rainbow1729651.aspx. [Accessed 2018].

[54] R. Dansie, "Open Game Art," 23 Februari 2014. [Online]. Available: https://opengameart.org/content/round-animals. [Accessed Oktober 2018].

[55] Reza, "Foxy Toon," 22 Juli 2016. [Online]. Available: http://foxytoon.co/2016/07/22/cartoon-farm/. [Accessed Oktober 2018].

[56] Soundbible, "Sound Bible," 2017. [Online]. Available: http://soundbible.com/tags-game.html. [Accessed 2018]. 